\section{MOLLY BLOOM: NĀO O MITO, MAS A MULHER}

BERNARDINA DA SILVEIRA PINHEIRO

Se a temática do romance Ulysses de James Joyce é amor e vida, Molly é a personificação da vida. Em carta a Frank Budgen, Joyce define seu personagem feminino Molly Bloom como uma mulher "perfeitamente sã de espírito, totalmente amoral, fertilizável, inconfiável, cativante, perspicaz, limitada, prudente, indiferente" - "Ich bin das Fleisch das stets bejaht" 1 ou seja, eu sou a carne que constantemente afirma. Ela realmente diz sim à vida, no sentido mais amplo da palavra.

Às vezes mesmo ingênua, porque espontânea, romântica, extremamente e inconformadamente solitária, Molly incorpora todas as mulheres, da virgem imaculada à prostituta - assim as teriam visto Stephen Dedalus e o jovem Joyce. Para aqueles que tiveram o privilégio de ler a extraordinária biografia de Joyce da autoria de Richard Ellmann, é ainda possível identificar em Molly traços de personalidade e reflexos de circunstâncias de vida de Nora Barnacle, assim como projeções do próprio Joyce, para quem, poderíamos dizer, ela seria o ideal da mulher, por ser inclusive aquela que se entrega ao sexo sem vislumbre de culpa.

Na verdade, a frivolidade de que alguns críticos a acusam, traduzida por sua preocupação com o corpo, com roupas que a enfeitem e a tornem mais atraente para os homens, é também uma preocupação constante de Joyce, como é possível evidenciar em suas cartas à mulher ausente de casa, ele escrevia à Nora, pedindo-lhe que comprasse vestidos bonitos e se enfeitasse para recebê-lo e cativá-lo. Ele mesmo, desde o início de sua união - fase financeiramente penosa de sua vida - gastava dinheiro às vezes indispensável à manutenção Stanislaus, com o objetivo de embelezar a mulher que amava. Se Molly é dotada de formas arredondadas, realiza o sonho de Joyce em relação a Nora, a quem pedia que se alimentasse bem a fim de adquirir a silhueta sedutora que almejava ver na mulher. Finalmente, a existên se e desfrutasse o sexo, sem qualquer sentimento de culpa, respondia à imagem do ideal femixino de Joyce, como é possível o perceber desde Stephen
Hero.

No entanto, o próprio Joyce não escapa ao preconceito social da época, pois, ao declarar que o último episódio de seu livro, "Penelope", é provavelmente o mais obsceno do romance, está assim condenando implicitamente Molly, parecendo ter esquecido as fantasias eróticas e pervertidas de Bloom,

Bernardina da Silveira Pinheiro é professora na Universidade Federal do Rio de Janeiro. 1JOYCE. p.170 “... perfectly sane full amoral fertilisable untrustworthy engaging
shrewd limited prudent indifferent Weib. Ich bin das Fleish das atets belalt" no episódio "Circe".2 E, contudo, capaz de intuir melhor do que ninguém as reações e sentimentos de uma mulher da classe média, não particularmente letrada, que vive apenas de suas atribuições caseiras. Quando, por exemplo, Bloom de madrugada, se deita ao lado de Molly, fala-lhe sobre o jovem Stephen, que trouxera até em casa para conversarem, dá-lhe uma desculpa pouco convincente por ter chegado tão tarde e, tranquilamente, pede que ela lhe traga na cama o café da manhã, Molly se espanta. Qual a razão de tão súbita mudança? Uma mulher, talvez? O pedido inusitado a intriga e determina o fluxo de seus pensamentos...

Vêm-lhe então à lembrança os homens que conhecera, as dificuldades financeiras que tivera de enfrentar ao lado do marido, os problemas de relacionamento com a filha adolescente, Milly, sua nova experiência sexual com Boylan, naquela tarde. E, assim, vamos tomando contacto com a figura complexa que é Molly Bloom.

Percebemos, em suas recordações da meninice e adolescência em Gilbraltar, que foi criada por um pai, militar, que às vezes bebia excessivamente, e por uma senhora, Rubio, que, segundo Molly, era velha, feia e dotada de uma religião dominadora. Quanto à mãe, como ela o confessa, "nunca a tivera".3 Em Gibraltar fez amizade com uma moça, Hester, mais velha do que ela, casada, que foi, pelo que se pode perceber, sua única amiga verdadeira. Quando Hester parte, Molly sofre muito e é tamanha a sua solidão que ela escreve cartas para si mesma - são as únicas que recebe. Mesmo naquele dia de manhã, recebera apenas um cartão da filha - que escrevera, contudo, uma carta para o pai - e o bilhete de Boylan, marcando com ela o encontro à tarde. E gostaria tanto de receber uma carta de amor, pensa. Já o sugerira a Boylan, mas não tinha esperança de ver seu sonho concretizado. Sente falta de carinho e, em pensamento, protesta contra a frieza de Bloom, que nunca a abraça, e "uma mulher quer ser abraçada, beijada, vinte vezes ao dia, desde que ela esteja apaixonada ou seja amada, se o homem que quer não está ao seu lado".4 Bloom sai, tem amigos com quem pode conversar e ela não tem nenhum. Além do mais os homens têm direito de ser exigentes na escolha da mulher que desejam para si enquanto elas thes servem de joguete nas mãos, são escravizadas - mas eles não vão escravizá-la, não.

Pensa no filho que perdeu pequenino e uma tristeza profunda a invade, mas reage contra ela.

As palavras que Bloom the dissera ao deitar somadas à relação sexual com Boylan, à tarde, que lhe proporcionara tanto prazer físico, trazem-lhe a mente os outros homens que conhecera; não tantos, contudo, quanto os listados por Bloom naquele dia. Lembra-se, por exemplo, do primeiro namorado em Gibraltar, Mulvey, e daquele que o sucedera, um jovem oficial inglês, Gardner, de quem gostara muito e que a deixara por ter de partir para a guerra, lá morrendo. Outros se sucederam em seus pensamentos, homens

Id. 0.170 "... Though probably more obscene than any preceding episode..." 3 JOYCE, p. 640

II d. D. 639 "... a woman wants to be embraced 20 times a day (...) no matter by who io lens as to be in love or loved by somebody if the fellow you want isn't there".

Orมaลอก $16 / 1909$ 
que por ela se sentiram atraídos ou que dela tentaram se aproveitar, como Lenehan, que descreve como o homem desprezível que é.

Em todas estas recordações, volta-lhe sempre à mente a figura do marido. Na verdade, se Bloom tem Molly permanentemente em seus pensamentos durante todo aquele dia tão longo, angustiado e atribulado, Molly a ele sempre retorna em seu monólogo particularmente extenso. Estava, portanto, certo Frank Budgen ao dizer que "Tanto Bloom quanto Molly têm isso em coto Frank Budgen ao dizer que "Tanto Bloom quanto
mum, extraem da inconstância tributos à fidelidade".

Molly é aquela mulher acusada de promiscuidade e de obscenidade. No entanto, segundo Marilyn French, embora fosse "a sexualidade encarnada", 5 Molly não traíra o marido durante os dez anos que se seguiram à morte do filho, Rubi. Justifica a conclusão através do próprio monólogo. De Gardner e de D'Arcy, Molly lembra apenas o beijo trocado, deste último o que lhe dera na igreja, tratamento, por conseguinte, bem diverso da descrição minuciosa e bastante explícita do encontro e da relação sexual que tivera com Boylan. 6

Ao repensar neste encontro, Molly se dá conta da atitude brutal do amante que a usara como um objeto, preocupado exclusivamente com o próprio prazer. Compara-o, então, a Bloom e vê quão diferentes eles são. Bloom sabe como tratar uma mulher; é delicado, cuidadoso. Ele sabia como possuir uma mulher. Lembra, então, do primeiro encontro com o marido, belo como Lord Byron, e do dia em que, depois de um beijo longo e inesquecivel, the disse o sim que ele ansiava ouvir

Às lembranças positivas que tem de Bloom, entremeiam-se outras. Algumas confirmam o que dele já sabíamos, seu voyerismo, fetichismo, suas perversões - embora diversas das a nós apresentadas em suas fantasias eróticas - contra as quais ela a principio reagira, mas em seguida acedera, como loucuras do marido que só ela conseguia compreender. Protesta, em pensamento, por Bloom estar agora vagando pela casa por falta de um emprego fixo. Ele não parava nos empregos, ora por envolvimento com movimentos políticos pela independência da Irlanda, ora por ter sido descoberto que ele era macon, ora ainda por seu temperamento obstinado e rebelde. Quando parecia que as coisas estavam melhorando, tudo degringolava novamente. Molly gostaria tanto que ele tivesse um emprego estável, com um salário regular, que the desse mais dinheiro do que aquele destinado apenas a manutenção da casa. Lembra-se, também, das promessas que Bloom lhe fizera enquanto namoravam; dar-lhe-ia tudo que ela quisesse, era só ela the pedir que ele, prometia, lhe daria, até uma viagem de lua-de-mel a Veneza, se ela o desejasse. Tudo pura imaginação, fantasia. Assim mesmo, era bom e atencioso com as pessoas idosas, com os subalternos, e esse aspecto ela apreciava muito nele.

Molly, no entanto, também é fantasia. Pensa na ida a Belfast, em sua tournée de concertos de canto, só com Boylan, seu empresário e agora amante. E se imagina ficando com ele, que é rico, pode the comprar coisas bonitas, não voltando mais para Dublin. Percebe, contudo, rapidamente,

\section{FRENCH. p.258.}

6Id. p.254. a impraticabilidade do sonho. Boylan não é homem de casar. Não param aí, entretanto, suas fantasias. Pensa em Stephen, que conhecera pequeno e de quem Bloom the falara antes de adormecer. Era ele agora um belo rapaz, inteligente, culto, um poeta. Bloom the dissera que Stephen lhe daria aulas de italiano. A princípio se revoltara em pensar que o marido mostrara seu retrato ao jovem, como se estivesse the oferecendo a mulher. Em seguida embarca em sua fantasia de uma vida a três, quem sabe na Espanha ou mesmo em sua casa. Ele seria seu professor de italiano e ela lhe daria aulas sobre o amor, a vida, seria sua musa inspiradora. Nesta altura, Boylan fora esquecido.

De Stephen, seu pensamento volta a Bloom e ao pedido que lhe fizera - a the dar ordens, "sentado rígido como o rei do país" 7 - e, daí, às compras que faria para preparar para o marido um café da manhã lauto e saboroso. Decide, então, fazer a última tentativa de derrubar o muro sexual que os separa. Primeiro, imagina fazê-lo de maneira violenta, agressiva, perversa, como se estivesse possuída de raiva, do desejo de lhe dar o troco por todas as suas frustrações, pelas perversões de que fora objeto; em seguida percebe não ser este o caminho a seguir. Cabe-lhe fazer Bloom desejá-la e muito; seduzi-lo; planeja, então, como conseguir seu intento. Há assim, talvez, uma possibilidade de triunfo para Bloom, bem diversa da vitória violenta do Ulisses clássico.

Esta é uma visão sugestiva, das muitas possíveis, da Molly mulher e amante.

A Molly mãe é igual a muitas outras. Seu relacionamento com a filha, Milly, adolescente de 15 anos de idade, é aquele de uma mãe que, subitamente, se defronta com a realidade de uma filha que está se tornando mulher e, de certa forma, ameaça suplantá-la. Milly agora a desafia, dirige-se a ela com petulância, não the obedece. Sai, volta tarde à noite, fuma e tudo isso aflige Molly. Mimada pelo pai, com ele conversa, ignorando a mãe, que se sente rejeitada por ambos. Molly sabe, contudo, que a qualquer problema que surja Milly recorrerá a ela. Revê na filha sua própria adolescência. Milly namora dois rapazes que são irmãos, sabe que é cativante e explora seus dotes. Um quadro, por conseguinte, bastante normal na fase de vida das duas, mãe e filha.

Joyce declarara a Louis Gillet que "procurara terminar o monólogo com a palavra menos forte que pudera encontrar. Encontrara a palavra 'yes', que é apenas pronunciada, que denota aquiescência, abandono de si próprio, relaxamento, o fim de toda resistência. 8

E assim termina o monólogo. Quando Molly está prestes a adormecer, confundem-se em sua mente cenários de Gibraltar e aqueles de Dublin, aos quais diz Sim; lembrança do primeiro namorado, ao qual diz Sim, do dia daquele beijo longo e inesquecível trocado entre ela e Bloom, ao qual diz Sim. E ela diz Sim, Sim, Sim, à vida e ao amor, Sim ...

JOYCE, p.628 "sitting up like the king of the country"

BILIMANN, p.712n "I had sought to end with the least forcerul word I could possibly find, I had found the word yes, wich is barely pronounced, which denotes acquiescence, reif abanden, relaxation, the end of all resistence". 


\section{REFERÊNCIAS BIBLIOGRĀFICAS}

BROWN, Richard. James Joyce and sexuality. Cambridge, Cambridge University Press, 1985.

BUDGEN, Frank. James Joyce and the making of "Ulysses": and other writings.

London, Oxford University Press, 1972.

ELLMANN, Richard. James Joyce. New and Revised Edition. Oxford, Oxford University Press, 1983.

. Ulysses on the liffey. London, Faber and Faber, 1974.

FRENCH, Marilym. The book as world: James Joyce's Ulysses. Great Britain, Abacus, 1982.

JOYCE, James. Letters of James Joyce. Ed. Stuart Gilbert. London, Faber and Faber, 1957.

Ulysses. The corrected text, with a new preface by Richard Ellmann.

Harmondsworth, Penguin Boocks, 1986.

SCOTT, Bonnie Kime. Joyce and feminism. Indiana, Indiana University Press, 1984. 